\title{
Coordinated fuzzy operation of battery energy storage and resistive brake for mitigation of SSR oscillations
}

\author{
Mohamed Fayez ${ }^{{ }^{*}} \mathbb{D}$, Fahmy Bendary ${ }^{2}$, Mohamed El-Hadidy ${ }^{3}$ and Mohamed Mandor ${ }^{2}$
}

\author{
*Correspondence: \\ eng_mf69@yahoo.com \\ ${ }^{1}$ Cairo Electricity Production \\ Company (CEPC), Cairo, \\ Egypt \\ Full list of author information \\ is available at the end of the \\ article
}

\begin{abstract}
The work presented herein is focusing on mitigating sub-synchronous-resonance (SSR) oscillatory torque and speed responses developed in power network equipped with series capacitor compensation as an outcome of the network perturbations. The mitigation effect of a battery-energy-storage (BES) controlled via a fuzzy-logic-controller (FLC) is explored. It is also explored accompanied by a fuzzy-bases resistor brake controlled via FLC. The IEEE second benchmark system is selected as a test grid under the $M A T L A B^{\mathrm{TM}} /$ Simulink simulation environment. The signal utilized for the propositioned controller is the alternator rotor speed deviation. The key conclusions of this investigation are the employment of a BES in the discharging mode alone might be utilized to alleviate the SSR relative speed, and torque oscillations, the BES employment accompanied with dynamic resistive brake is supplying faster-decaying rates for the SSR oscillations in observation with the BES employment only.
\end{abstract}

Keywords: Battery energy storage, Fuzzy logic control, MATLAB/simulink, Dynamic resistive brake

\section{Introduction}

Steam turbines produce the mechanical torque required to revolve the synchronous machines at their rated speeds. The mechanical torque developed in turbogenerator rotary shaft is constant in magnitude, as long as the steam flow is steady, and unidirectional. At normal conditions, the electromagnetic torque developed in the gas, or air, gap of the machine, or more specifically the alternator gas gap, balances the mechanical toque which preserves fixed rotational speed. The turbogenerator rotary shaft is tied electromagnetically to the network via the alternator electromagnetic torque. The different grid perturbations cause a periodic interchange among the various components of grid [1]. When such energy interchange occurred among the network and turbinegenerator, it is commonly called torsional dynamic interaction with turbogenerators accompanied by mechanical torque oscillations at the distinctive shaft sections. When these torque oscillations have frequencies coincident or close to the natural modes of torsional oscillations of the embroiled rotary shaft, a resonant condition is fulfilled which is commonly called subsynchronous resonance (SSR) with the accompanying

(c) The Author(s) 2021. This article is licensed under a Creative Commons Attribution 4.0 International License, which permits use, sharing, adaptation, distribution and reproduction in any medium or format, as long as you give appropriate credit to the original author(s) and the source, provide a link to the Creative Commons licence, and indicate if changes were made. The images or other third party material in this article are included in the article's Creative Commons licence, unless indicated otherwise in a credit line to the material. If material is not included in the article's Creative Commons licence and your intended use is not permitted by statutory regulation or exceeds the permitted use, you will need to obtain permission directly from the copyright holder. To view a copy of this licence, visit http://creativecommons. org/licenses/by/4.0/. 
severe mechanical stresses along the rotary shafts of turbogenerators. SSR is basically a resonant circumstance evolved as a correlative outcome for series capacitor compensation [2].

The applying of series capacitor banks in lengthy transmission corridors, generally more than $240 \mathrm{~km}$, has been long recognized as posing a potential hazard to steam prime movers driving synchronous machines after the unfortunate Mohave shaft failure incidents back in the seventies [3-6]. It has been broadly utilized since the early fifties for transferring large blocks of electric power over lengthy transfer distances in a cost-effective approach [3]. The utilities have gained so many overwhelming merits from series capacitor banks which making it extremely indispensable for long transmission corridors [3-5]. Series compensation allows for heavier power transactions through the existing transmission facilities without the urge for constructing additional transmission projects [3]. It also enhances the voltage profiles of the connected busses, and thereby the threshold of voltage instability is consolidated [4]. Moreover, network angular stability is boosted via series capacitor banks [3]. Power grids incorporated with series capacitance elements are highly vulnerable to be exposed to SSR conditions, at certain compensation levels, where the rotor system of steam turbogenerators and the network is exchanging energy at one of the torsional resonance modes of oscillations [6].

In fact, SSR is a dilemma of overwhelming attention inside the engineering society. SSR is a transmission-based dynamic interaction problem that has adverse devastating outcomes on the steam turbogenerators working under these circumstances [7]. Therefore, SSR is considered an interdisciplinary dynamic problem. From a mechanical perspective, SSR causes devastating torsional mechanical torque vibrations, or oscillations, distinguished by their ever-rising peaks at the connecting shaft sections resulting in a complete fatigue life loss of the machine shaft forging [8]. The rotary shaft is then unquestionably destined to encounter irrevocable low-cycle fatigue surface cracks that could be the precursor to an inevitable completed fracture of the machine shaft [9]. In 1970, a cross-compound turbogenerator set with 909 MVA rating located at Mohave coal-fired electricity production facility in Southern Nevada, California, USA, had suffered from exciter shaft failure. The failure was exactly at the 483 MVA high pressure, full-speed-alternator of the cross-compound exciter unit. The collector ring located at the shaft segment between exciter shaft and the alternator was melted down. The metallurgical analysis was conducted to discover the intrinsic cause behind the failure, and the results proved that the shaft forging had experienced fatigue leading with cyclic nature led to plastic deformation (plasticity or plastic yielding) of the metallic shaft. The root cause associated with the failure was not identified at that time which led to another virtually similar accident at the same unit in Mohave power plant twelve months later $[8$, 9].

The SSR-related mechanical working of the metallic shaft caused heating of the affected shaft section which led to the thermal breakdown level of the collector rings. The consequent arcing energy between the negative and positive DC power feeding bars caused a huge gap in the rotor forging $[8,9]$.

It is recognized in much recent literature that the fast-growing raise of BESs is highly expected in power grids in the time to come because of the ceaseless transition of many countries to have higher solar PV and wind permeation levels in their energy portfolios 
[10-12]. The development of multi-MW scale BESs accomplishes a very significant task of amalgamating the resources of renewable energy with the dispatchable load by extenuating the intermittence behavior of solar PV and wind resources [10].

Electrical networks have many real-life examples of multi-MW scale BESs upon the escalated developmental accomplishments in the scopes of power converters and batteries technology [13]. Multi-MW scale BES units are acknowledged as a substantial engineering breakthroughs in electrical engineering and have recently been paid much more attention by utility, industry, and academia [14]. Applications for BESs in electrical networks are numerous such as regulating the grid frequency, shaving peak loads, relieving electric transmission congestion, improving the grid voltage profile, extenuating the intermittence behavior of the renewable energy resources, charging an electric vehicle, and enhancing the grid reliability $[14,15]$.

Other applications involve load following for heavy load variations, mitigation of lowfrequency inter-area power oscillations, contributing in the restoration procedures as a quick start reserve for complete blackout accidents, and providing "Arbitrage" which is simply a process of timely shifting of electric energy [13, 16, 17].

$\mathrm{Pb}$-acid BES has been broadly implemented in Multi-MW storage facilities upon their relative cheapness, high response time, reasonable reliability, minor daily self-discharge, high level of maturity in the industry, and virtually complete recyclability [18-20]. The researching and developing activities on $\mathrm{Pb}$-acid battery banks have been underway for over 160 years since their invention by the French scientist Gaston Plante [19]. Pb-acid battery banks have been so long implemented in the greater majority of real-life applications [20].

The first Multi-MW scale Pb-acid-based BES project was a 14 MWhr BEWAG storage facility which was commissioned in 1986 at Berlin, Germany. It was utilized as a spinning reserve asset and as a grid frequency regulator for western Berlin. In 1988, a utility company in a $40 \mathrm{MWh} \mathrm{Pb}$-acid BES project was commissioned at Chino substation, California, USA. It was used as a peak load shaver, electric load leveler, grid frequency controller, grid voltage controller, low-frequency power oscillations damper, and a black starter asset for the grid for blackout events [18, 19]. In 1994, a 14 MWhr Pb-acid-based BES project was built in Puerto Rico for providing voltage and frequency support in the grid. In South Africa, another grid-scale $\mathrm{Pb}$-acid BES was commissioned for providing peak shaving power in the peak periods [19].

Reducing the speed deviations of the neighboring turbogenerators is a crucial element in any mitigatory countermeasures for the torsional oscillations. BES achieves fast injections and absorptions of real power at the common-coupling-point (CCP) which contributes in decreasing the deviations in the shaft speeds of the neighboring turbogenerators [21].

However, the swift charging and discharging strokes, exceptionally in mitigating the high torsional oscillations distinguished by their relatively high frequency, will have severe deteriorations in the life span expectations of the embroiled battery bank [21, 22]. Therefore, only real power injections are adopted herein. Nevertheless, the estimation of the life span of the embroiled battery bank is not the prime subject of this work.

The remaining parts of this investigation will be arranged as follows. The second section concisely illustrates the test grid under consideration. The third section provides the 
introductory concepts of utilizing FLC to coordinate the power injections of BES and the braking interventions of a resistive dynamic brake. The fourth section displays the MAT$\mathrm{LAB}^{\mathrm{TM}} /$ Simulink comparative simulation results with discussions. The fifth section concludes by emphasizing the key conclusions of this work. Finally, the references utilized in this investigation are listed.

\section{Test system description and system modeling}

The well-known IEEE second benchmark model is adopted herein to examine the capability and the effectivity of BES and resistive brake controlled by two independent FLCs on tempering the SSR oscillations. Figure 1 depicts the benchmark together with the detailed mechanical turbogenerator rotary shaft system.

It is comprised of an alternator, rated at $600 \mathrm{MVA}, 22 \mathrm{kV}$, and $3600 \mathrm{rpm}$, feeding the network generator step-up (GSU) transformer, rated at $600 \mathrm{MVA}, 22 \mathrm{kV}: 500 \mathrm{kV}$, and double extra-high voltage (EHV) transmission lines [19]. Transmission line (A) is equipped with a series capacitance element. The data for the alternator and the lines are borrowed from Ref. [23].

The synchronous machine is driven by one double-flow Low-Pressure (LP), and one High-Pressure (HP) steam turbines connected in tandem configuration. The two turbine sections are equally sharing the mechanical driving torque, i.e., the sharing mechanical torque fractions are $50 \%$, and $50 \%$, respectively. The detailed turbogenerator rotary shaft mechanical parameters are borrowed from Ref. [23]. In this work, a BES of 200 megawatt-hour (MWhr) capacity is interfaced to the transmission system through a $1 \mathrm{kV}: 500 \mathrm{kV}$ step-up transformer.

A schematic of a conventional grid-interfaced BES is pictured in Fig. 2. Practically, a gridinterfaced BES is comprised of a battery bank, DC-to-AC inverter, passive inductance filter, and transformer which is necessary to raise the voltage level and connect the BES to

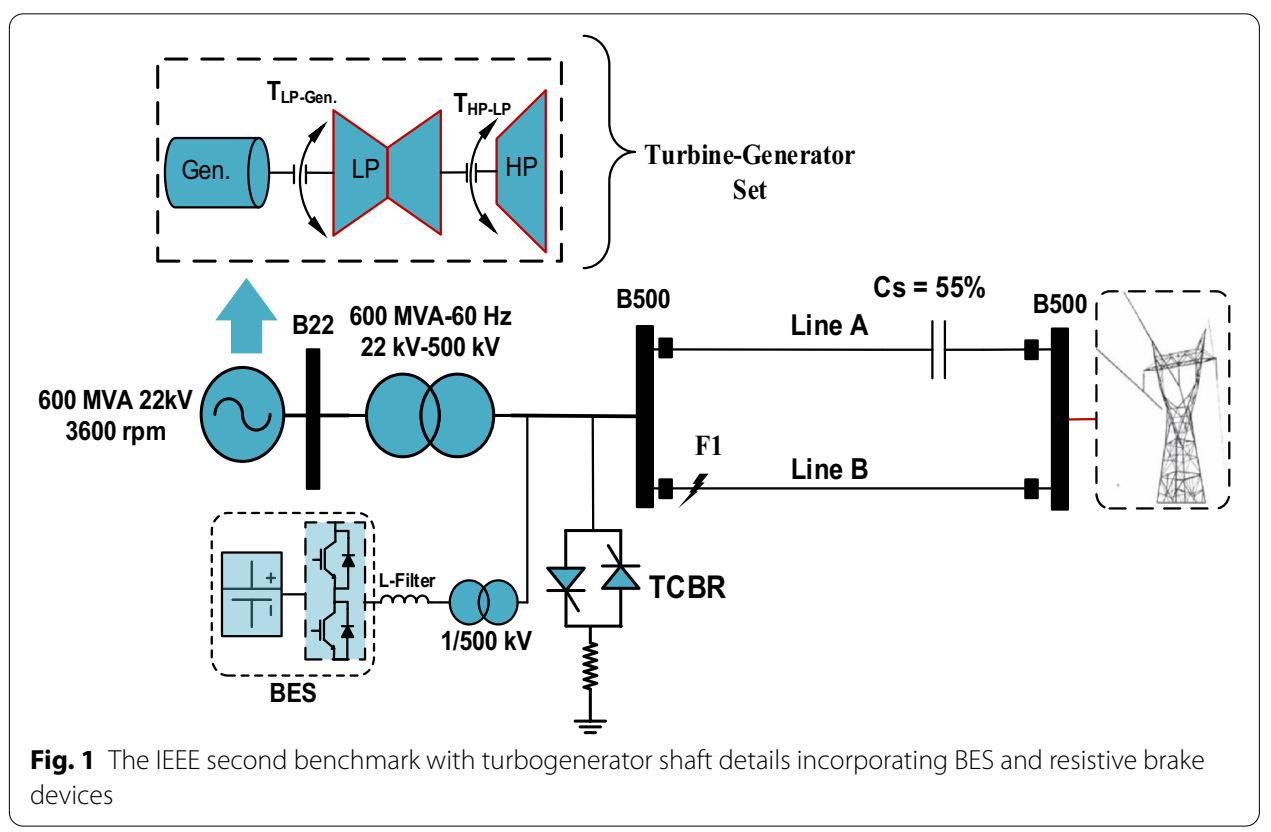




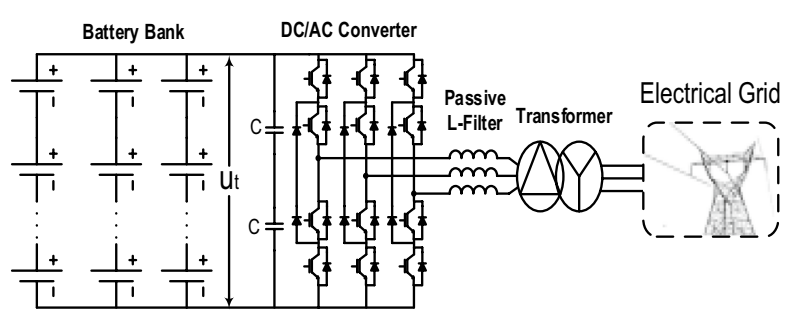

Fig. 2 Typical structure of BES interfaced to the transmission power grid

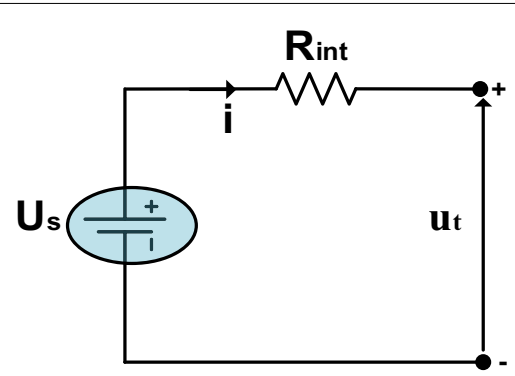

Fig. 3 Diagram of Shepherd's battery model

the transmission grid. The DC power produced via the battery bank is transformed into 3-phase AC power through a 3-level neutral-point-clamped (NPC) DC-to-AC power converter and grid interconnected via an inductance filter and a transformer utilized for stepping up the voltage. It is well-known that the DC-to-AC power converters with 3-level NPC topology are a prevalent topology for BES applications in practical real-life; therefore, it will be implemented in this investigation. Also, it is of great benefit to mention that the passive inductance filtering element is among the most frequently implemented in the networkinterfaced inverters [24]; therefore, it will be implemented in this article.

The modified Shepherd $\left(R_{\text {int }}\right)$ model is chosen in this investigation to model the battery system which has been broadly implemented in many articles of the literature since it is distinguished by its simpleness and matureness. It is simply a DC potential source characterized by its State of Charge (SoC) dependency connected in series to the battery inner resistance $\left(R_{\text {int }}\right)$ as it is pictured in the outline of Fig. 3 [24]. The $R_{\text {int }}$ battery model was introduced to the academic community in the mid-nineties of the previous century, and it is distinguished by its simpleness [25].

The voltage at battery terminals, $u_{t}$, can be obtained as follows during the discharging phase and for the charging phase, respectively, as [24]:

$$
\begin{aligned}
& u_{t}=U_{s}-K\left(\frac{Q}{Q-i t}\right) i-K\left(\frac{Q}{Q-i t}\right) i t-R_{i n t} \times i+\varepsilon \\
& u_{t}=U_{s}-K\left(\frac{Q}{i t-Q}\right) i-K\left(\frac{Q}{Q-i t}\right) i t-R_{i n t} \times i+\varepsilon
\end{aligned}
$$




$$
\frac{d \varepsilon}{d t}=B \times|i| \times(-\varepsilon+A \times u)
$$

where $i$ represents the current (in amperes), $Q$ represents the maximum battery bank stored charge in Ampere Hour (Ah), it represents the present battery charge (in Ah), Us represents the constant open-circuit voltage at battery terminals (in volts), $K$ represents the polarization curve slope (in $\mathrm{V} / \mathrm{Ah}$ ), $\mathrm{R}_{\text {int }}$ represents the battery inner resistance (in $\mathrm{ohm}), A$ and $B$ represent empirical parameters, and finally, u represents a binary variable that takes 1 for the mode of charging and 0 elsewhere. The DC-AC power converter is modeled by employing a 3-level Insulated-Gate-Bipolar-Transistor (IGBT) bridge with pulse-width-modulation (PWM) control. A phase-locked-loop (PLL) is implemented to synchronously interconnect the BES to the network. The Voltage-Source-Converter (VSC) inverter current control in a revolving (synchronous) frame via a ProportionalIntegral (PI) controller is implemented in this investigation as revealed in Fig. 4 [24].

Also, a DC voltage PI controller is exploited to determine the d-axis reference current $\left(i_{\text {dref }}\right)$ value. The q-axis current reference $\left(i_{\text {qref }}\right)$ is selected to be 0 to suspend the injections of reactive power and to allow for the injections of the real power only. Equation (4) provides the formulas for the dq voltages of the DC-to-AC power converter [24].

$$
\left[\begin{array}{l}
u_{d} \\
u_{q}
\end{array}\right]=L \frac{d}{d t}\left[\begin{array}{l}
i_{d} \\
i_{q}
\end{array}\right]+R\left[\begin{array}{l}
i_{d} \\
i_{q}
\end{array}\right]+\omega L \frac{d}{d t}\left[\begin{array}{c}
-i_{d} \\
i_{q}
\end{array}\right]+\left[\begin{array}{l}
e_{d} \\
e_{q}
\end{array}\right]
$$

In which $L$ represents the inductance between the inverter AC side and the CCP; $R$ represents the resistance between the $\mathrm{CCP}$ and inverter $\mathrm{AC}$ side; $e_{d}$ and $e_{q}$ represent the dq network voltage components; $u_{d}$ and $u_{q}$ represent the inverter AC output voltage dq components.

Additionally, a dynamic resistor brake will be utilized to consume the excess real power to obtain better profiles of the torsional torque. The conceptual principle a resistor brake is simply to momentarily energize an extra pseudo-electric load to consume

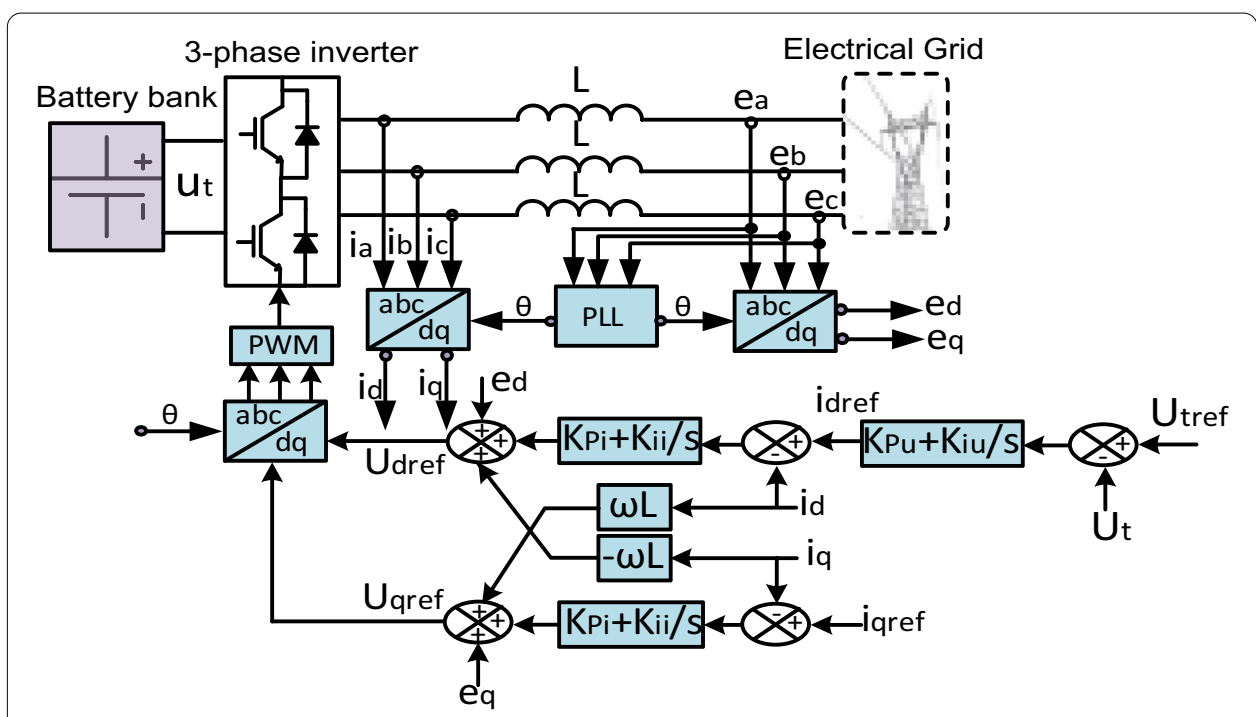

Fig. 4 PI controller structure synchronous reference frame for the employed BES 
the excess system energy developed during severe dynamic disturbances and de-energize it elsewhere. There are plenty of researches in the recent literature regarding resistor brake applications for augmentation of transient stability, alleviation of steam turbinegenerator multi-modal shaft torsional oscillations, and minimization of SSR oscillations in series compensated power systems by implementing a signal synthesized from alternator rotor speed. If a dynamic resistive brake is linked to the network by an AC-to-AC voltage regulator, it is given the acronym 'TCBR' for thyristor-controlled-brake-resistor. It is a specialized purpose FACTS element. TCBR is specialized FACTS since it is utilized in treating certain issues like mitigating the multi-modal torsional torque oscillations, minimizing the SSR oscillatory torque traces, and improving the system stability [26]. TCBR per-phase model contains double thyristors valves in back-to-back connection with a single braking resistor in series. In this work, a $200 \mathrm{MW}$ brake is also interfaced to the transmission system bus. The mitigation scheme relied on localized control signal represented by the speed of synchronous machine deviation to help the propositioned controllers decide the switching state of the TCBR, i.e., whether the brake is in service or not, and the instants of real power injections of the BES. Basically, the natural attenuation rates related to the SSR circumstances are distinguished by its very low values especially under low-load profiles [27]. Therefore, no-load condition is assumed for considering the most pessimistic case study.

\section{Fuzzy controller design}

The theorem of fuzzy-set (FS) was first presented to the academic society by the sole contribution of Zadeh in the mid-sixties. FS is simply an approach to interpret crisp values into changing degrees of belonging (or changing degrees of truth) using lingual variables. In the traditional (nonfuzzy, conventional, classic, hard, ordinary, or crisp) set, any separate element of the universe-of-discourse is either belonging to the set or is not belonging to the set. Thus, the degree of membership associated with any separate element is crisp value, i.e., it is either yes (in the set and takes the number 1) or no (not in the set and takes the number 0 ). In other words, FS is a generic form of the traditional set. FS is able to process the concepts and notions that humans use in their day-to-day life such as, "very high," "high," "medium," "low," and "very low" without the necessity to know the definite ranges associated with each concept [28].

Each FS is distinguished by a unique function that determines the degrees of belonging of crisp the values usually named the membership function (MF) which has a nonlinear nature and determines the degrees of belonging of crisp values associated with certain lingual variable utilizing a crisp value lying in the range from 1 to 0 . MF has many types, such as sigmoidal or s-shaped, triangular, generalized bell (GB), trapezoidal, and Gaussian. Therefore, the fuzzy logic, which is based upon the FS theory, resembles human thinking and reasoning depending on its reliance on changing degrees of belonging accompanied by the applying of lingual variables. Unlike its Boolean counterpart, which implements two levels of logic ( 1 or 0$)$, the fuzzy-logic implements logical levels of unlimited values lying between 1 and 0 to find solutions for issues that have uncertainties or ambiguous situations [28].

Despite its origin in the US during the mid-sixties along with its theoretic validation in the UK in during the mid-seventies, fuzzy-logic acquired a broad reputation 
among the peer community accompanied by practical real-life applications in Japan in the eighties. Fuzzy control is different from the traditional control in that it does not require a mathematical model of the system to be considered [28]. It regulates the inputs to obtain suitable outputs by simply scanning the present output of the system to be considered by depending on humanlike expert's decision procedures in regulating the plant inputs $[28,29]$. FLCs have been proposed for a variety of multidisciplinary network issues with the containment of a significant number of uncertainties since the early nineties [29]. It has been long identified as a very effective candidate for dealing with many issues such as, among others, generator's excitation voltage control, load frequency control, load forecasting, power flow analyzing, electromechanical oscillation damping, transient stability improving, blade-pitch angle controlling in wind turbines, DC link controlling in energy conversion systems, transformer fault diagnosing, and economic dispatching [29].

Fuzzy Rules, or "fuzzy linguistic conditional statement," "fuzzy if-then rule," "linguistic implication," "linguistic fuzzy information," "fuzzy implication" take the form "IF the rule antecedent or the premise, THEN the rule consequence or the conclusion," [30]. The linguistic fuzzy rules implementation are based upon the procedures performed by skillful humanly operators that do not require to study the mathematical model of the plant under their operation. The skilled humanly operators, with operating experience, modify the system inputs to acquire the desired output levels by just only observing the current system outputs without knowing the dynamics system and parameter variations [31]. The conception of fuzzy lingual (or linguistic) variable was first emerged to the peer community by Zadeh in 1971 as an alternate approach for simulating human intellectual thinking [30]. A fuzzy-rule may have various variables in the premise and/or in the conclusion parts. It can be multi-input-multioutput (MIMO), multi-input-single-output (MISO) single-input-single-output (SISO), or single-input-multi-output (SIMO) [31]. Fuzzy rules perform an essential role in exemplifying the practiced controlling/modeling knowledge and expertise and in interfacing the inputs of the fuzzy-logic systems to their output variables [32]. Fuzzy reasoning is inference proceedings utilizing the fuzzy-logic to conclude the final output from the utilized fuzzy rules and well-known certainties. Fuzzy reasoning builds mainly on two prime frameworks, namely fuzzy relations, and fuzzy extension principle. Fuzzy-rule is then interpreted into fuzzy relation using extension principle where the crisp domain is extended into the fuzzy domain using certain mapping techniques such as one-to-one mapping, one-to-many mapping, or many-to-one mapping [30].

There are two main types of fuzzy relations, namely unary fuzzy relations where the FS possesses a one-dimensional membership function, and binary fuzzy relations where the FS possesses a two-dimensional MF. Zadeh came up with a composition operation, called Maximum-Minimum (Max-Min) composition or Max-Min product, to obtain the fuzzy relations [30]. FLC is a rule-based controller of the nonlinear type that relies on the manipulation of the expert knowledge. FLCs introduce superior performance levels by exploiting the expert's knowledge conception in treating a broad variety of multidisciplinary control issues. The elementary configuration of generic FLC is typically comprised of the four primary stages: fuzzification, knowledge base, fuzzy-inferencesystem (FIS), and defuzzification which is graphically supported by Fig. 5 [31]. 


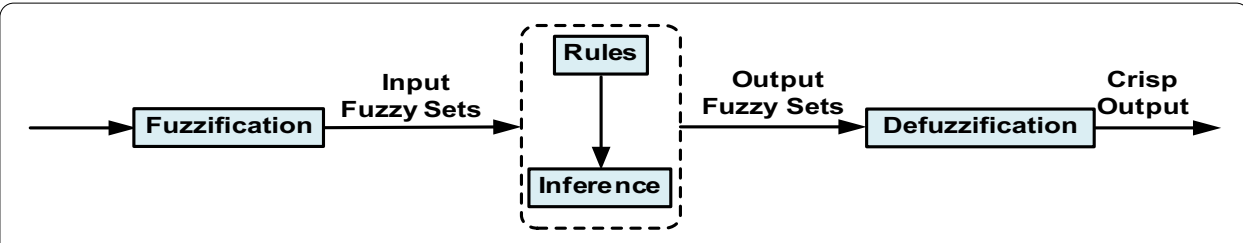

Fig. 5 General structure of FLC

Defuzzification is simply a mathematical averaging function, and it is the union of all the rule consequences of the embedded fuzzy rules [30,31]. There are six main techniques of defuzzification, namely centroid-of-area, the center-of-gravity, the bisector-ofarea or equal-of-area, mean-of-maximum, smallest-of-maximum, largest-of-maximum. The defuzzification procedures, mainly in FLC with Mamdani FIS, represent heavy computational burdens in real-life fuzzy applications [33]. Takagi-Sugeno (TS) controllers do not require the final defuzzification procedure since the involved output MF is either a linear-function or constant value, i.e., numerically represented, which makes the TS controllers more efficient than Mamdani controllers from the computational perspective [28-30]. An example of the TS fuzzy-rule is presented as follows [30]. For zero-order Sugeno fuzzy model, if the first input is $x$ and the second input is $y$, then output will be constant denoted by "c". For first-order Sugeno fuzzy model, if the first input is $x$ and the second input is $y$, then output will be $a x+b y+c$. A higher-order TS fuzzy model could be obtained if the rule consequent is a nonlinear equation, if the first input is $x$ and the second input is $y$, then output will be $a x^{2}+b y+c$. The aggregated output of all TS fuzzy rules is achieved either via "weighted average," or "weighted sum" operators which makes the time-consuming defuzzification process avoidable.

Many works of literature have proved that acquired damping levels from the employment of the alternator, or synchronous machine, speed deviation as an FLC input is much more enhanced than the levels achieved from employing other speed signals from the various shaft sections. Nonetheless, the alternator mass speed is not very challenging to capture suchlike the various steam turbine different sections speed deviations since the turbine is thermally insulated to decrease the thermal heat losses and also the steam prime mover rotor is rigorously sealed through a highly effective steam-sealing system [34]. So, the speed deviation pf the alternator mass in per-unit (p.u.), $\Delta \omega_{\mathrm{Gen}}$, is chosen as the FLC input and the output is fixed with either 1 or 0 . The FLC takes the appropriate action if the speed deviation signal $\left(\Delta \omega_{\text {Gen. }}\right)$ is different from the specified non-acting band based upon the equation given in (5):

$$
\Delta \omega_{\text {Gen. }}=\omega_{\text {Gen. }}-\omega_{0}
$$

where $\Delta \omega_{G e n}$. is the deviation of the alternator rotor angular speed in p.u., $\omega_{G e n}$. is the alternator rotor angular speed in p.u., and $\omega_{0}$ is the nominal alternator speed of rotation under normal conditions (it equals to 1 p.u.). The battery bank should inject real power if the $\Delta \omega_{G e n}$. is having negative values and should be in the idle operation mode (i.e., not charging or discharging) elsewhere. While the resistive brake should absorb real power if the $\Delta \omega_{G e n}$. is having positive values and should be out of service elsewhere. Three membership functions of the GB type are utilized to represent the inputs for the 
propositioned FLC and are portrayed in Fig. 6. The BES under consideration shall be selectively charged when the SoC falls below $85 \%$ upon normal system operating conditions to be ready for the varied awaited SSR events.

Three lingual variables, PD (Positive-Deviation), SD (Small-Deviation), and ND (Negative-Deviation), are defining the fuzziness of the FLC input speed signal for both controllers. Equation (6) introduces the expression of GB function utilized to determine the membership degree.

$$
\mu_{A}\left(\Delta \omega_{\text {Gen. }}\right)=\frac{1}{1+\left|\frac{\Delta \omega-c}{a}\right|^{2 b}}
$$

where $\mu_{A}\left(\Delta \omega_{G e n}\right)$ is the membership degree, the 'a' parameter decides the bandwidth of the MF curve, the 'b' parameter decides the width of the MF curve crispy top, and the 'c' parameter decides the MF curve center.

The propositioned FLC output is an invariant number possessing either 1 or 0 . Then, the rules employed for the BES controller will be, If $\left(\Delta \omega_{G e n}\right)$ is ND, then FLC output will be 1 , If $\left(\Delta \omega_{G e n}\right)$ is SD, then FLC output will be 0 , and finally If $\left(\Delta \omega_{G e n}\right)$ is PD, then FLC output will be 0 . In a corresponding manner, the rules employed for the resistive resistor brake FLC will be, If ( $\Delta \omega_{G e n}$.) is ND, then FLC output will be 0 , If $\left(\Delta \omega_{G e n}\right.$. $)$ is SD, then FLC output will be 0 , and finally If ( $\Delta \omega_{G e n}$.) is PD, then FLC output will be 1 . The output of the BES controller will be forwarded to the PWM control circuitry to decide either the BES will be in idle mode or discharging mode. Accordingly, the output of resistive brake FLC will be forwarded to the thyristor firing angle circuit to decide whether the resistor brake will be in-service or out of service. The switching strategy under consideration in this investigation is fuzzy-based discontinuous ON-OFF control in which the real power injection and dissipation moments are decided by the implemented FLCs.

\section{Results and discussion}

The propositioned scheme effectivity will be verified by conducting a simulation study in the time domain via the Simulink modeling and simulation platform. Transmission line B is subjected to three-phase to ground fault, near the generator HV bus at the disturbance point F1, as it is noticed in the outline of Fig. 1. The fault is a 1 cycle of

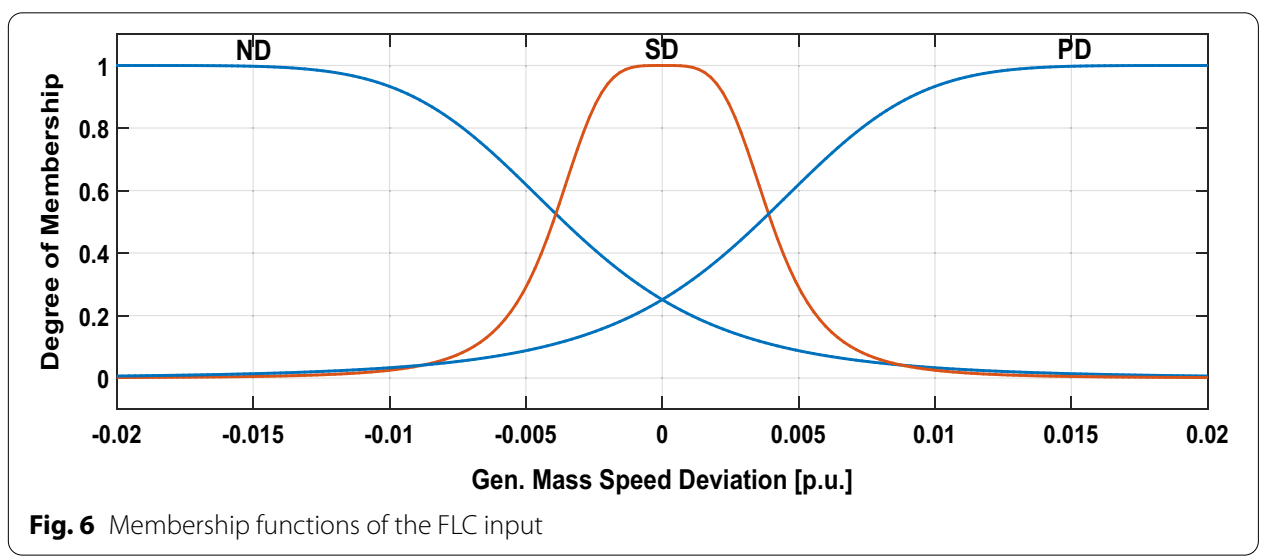


self-healing type, i.e., the embroiled CBs are not participating in severing the faulted line and is being applied at $0.0222 \mathrm{~s}$ from the simulation period. The rotor system torque and speed responses, in p.u., without any countermeasures, with only the BES, with only the TCBR, and with the TCBR along with the BES are presented in Fig. 7. Figure 8 delineates the comparative rotor system speed deviation response.

From the aforementioned simulation results described in Figs. 7 and 8, in the results without the propositioned scheme, it is discernibly observed that the torsional speed, and torque profiles have experienced intense oscillations with devastating magnitudes. Under these oscillations, the shaft structure is definitely destined to experience a severe reduction in its fatigue life expectancy. Because of the employment of the real power injections of fuzzy-based BES, or fuzzy-based TCBR, it is noticed that both of the relative speed and the responses the torsional torque of the shaft structure have encountered good supplemental damping. Also, the applying of the will with the BES substantially alleviate the torque and relative speed SSR oscillations in comparison with the BES alone. The BES helps mitigate the SSR torsional oscillations by injecting real power upon the deceleration moments. To elucidate the propositioned scheme functioning,

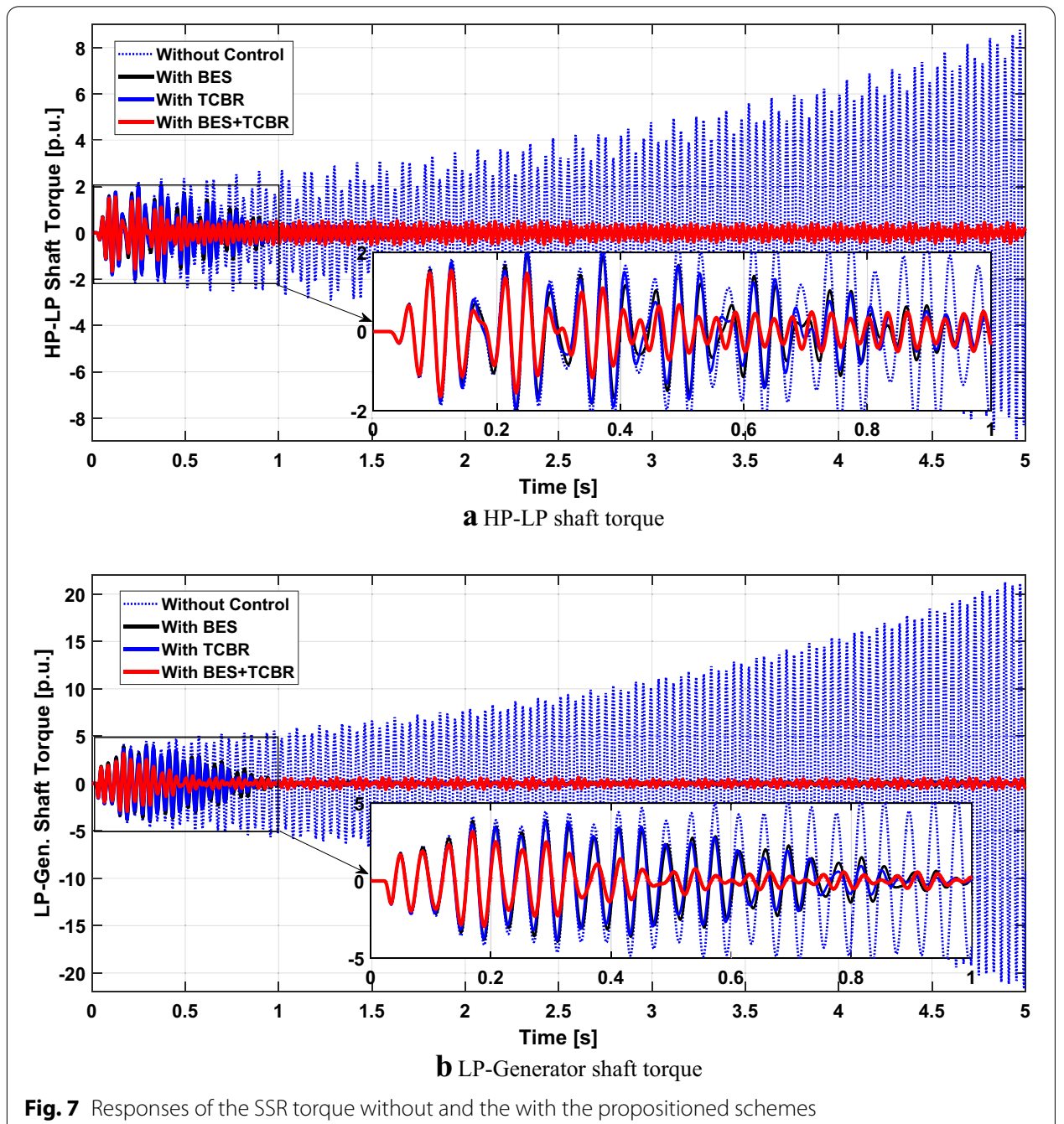




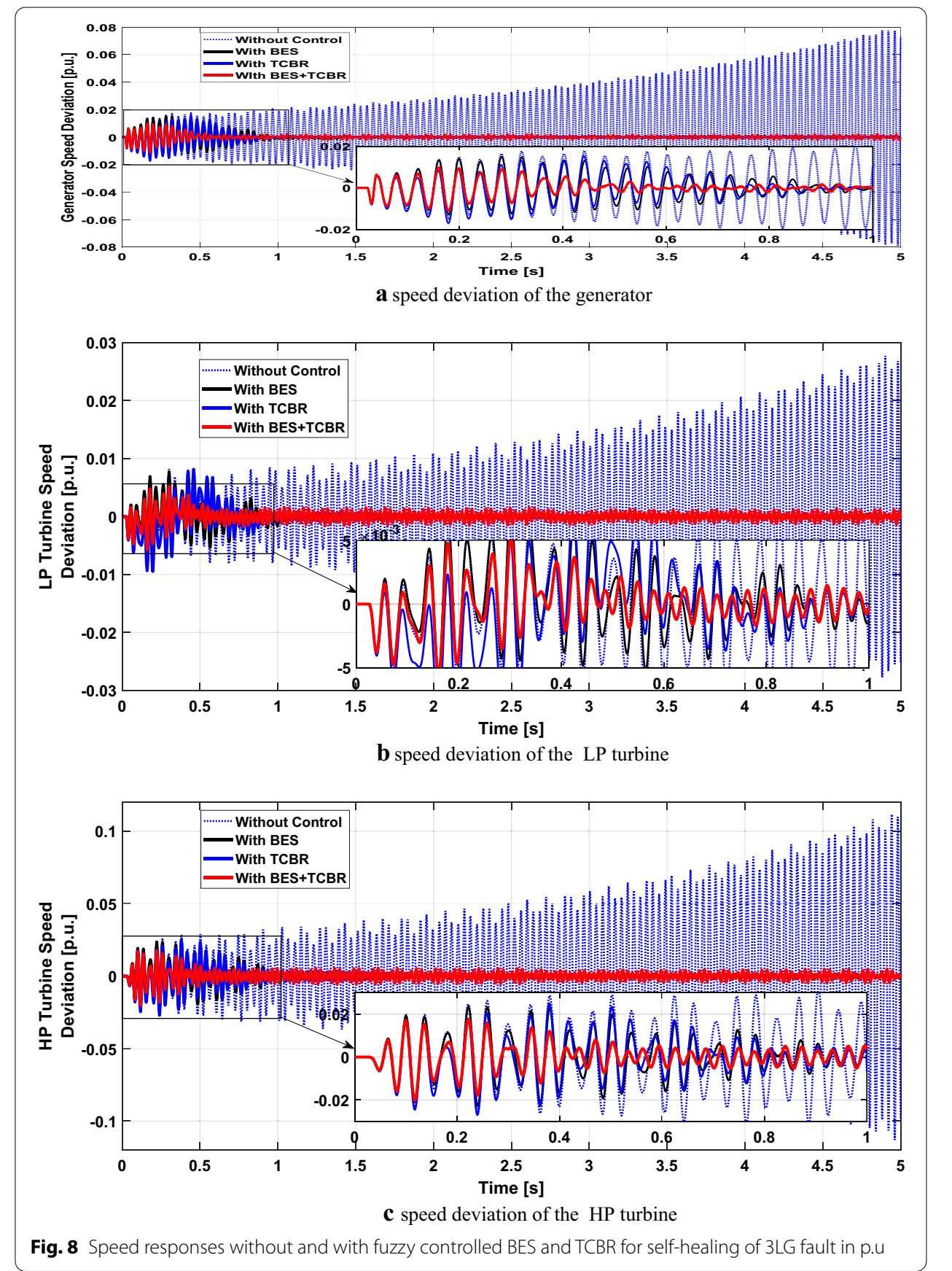

the responses of the BES real power injection without the dynamic brake and with the dynamic brake are portrayed in Fig. 9. Moreover, the dynamic brake power dissipation response is described in Fig. 10.

\section{Conclusions}

A coordinated fuzzy-based switching operation of TCBR and BES is proposed in herein to alleviate the mechanical SSR oscillations revealed upon the post-existence of series compacitor banks on lengthy transmission grids in this article. The propositioned 

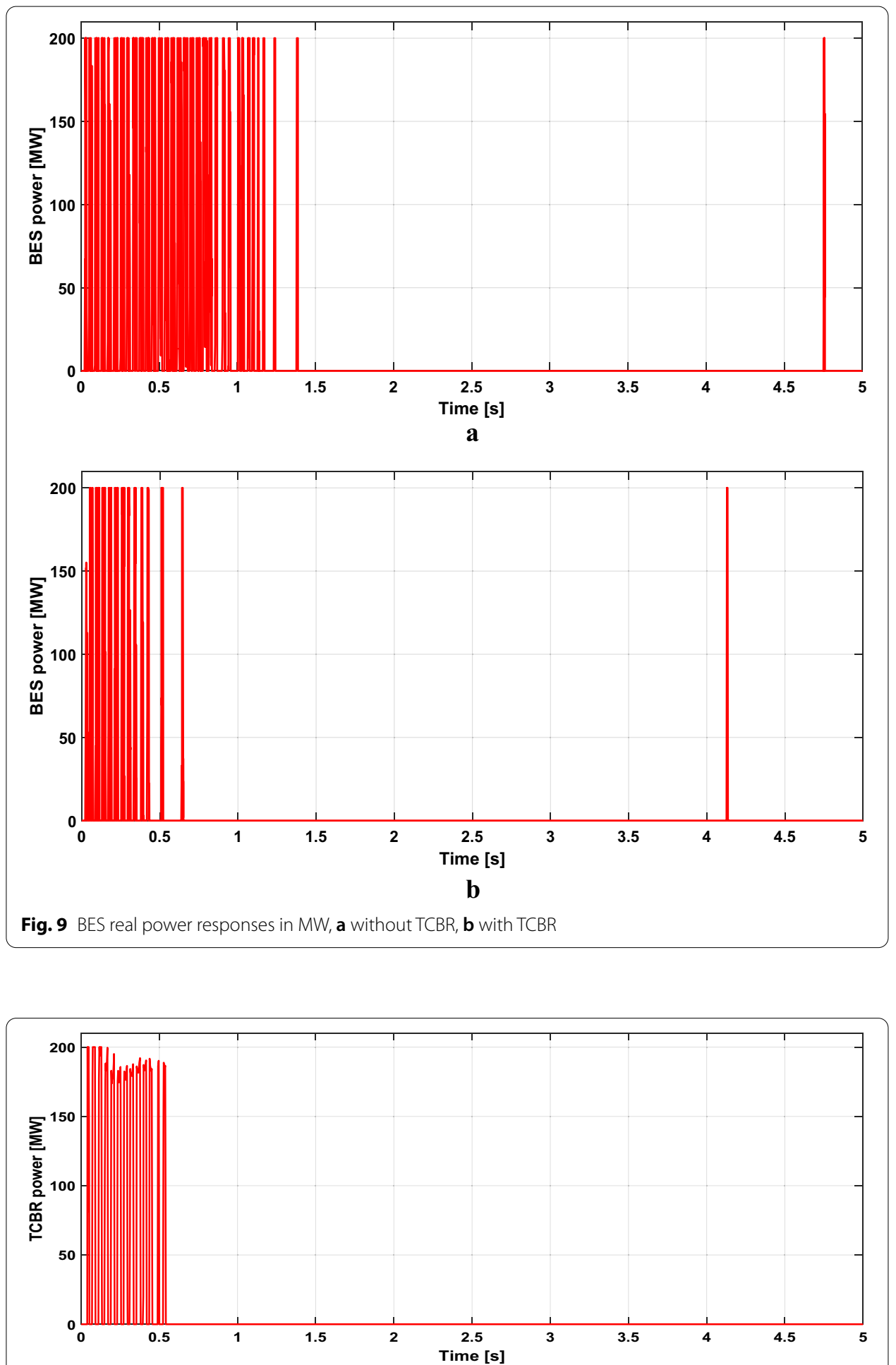

Fig. 10 TCBR three-phase dissipated power in [MW]

scheme was examined on the well-recognized IEEE second benchmark grid. The key conclusions of this investigation are that the employment of BES in the discharging mode alone might be utilized to alleviate the SSR oscillations, the BES employment 
accompanied with dynamic resistive brake is supplying faster-decaying rates for the SSR torsional oscillations in observation with the BES employment alone, and finally, the BES employment in the discharging mode only might help expand the lifetime expectancy of the embroiled battery bank. Furthermore, the propositioned mitigation scheme is distinguished by its simpleness since only 3 fuzzy rules are to be embroiled in the decision-making procedures which decreases the intensive computational burdens in actual applications.

\section{Appendix A: Power system data}

Steam-Turbine-and-Governor MATLAB/Simulink block is utilized to implement a twomass steam turbine. The turbine-generator shaft detailed mechanical data are in Table 1 [23].

Synchronous machine MATLAB/Simulink block is utilized in our study to implement the alternator herein, and the electrical parameters are in Table 2 [23].

Figure

11 depicts the electrical representation for the IEEE Second benchmark.

The ratio-of-compensation, $\mathrm{Xc}$, is set to be of $55 \%$ of the line " $\mathrm{A}$ " reactance. The IEEE second benchmark impedances are in Table 3 .

The BES parameters utilized herein are in Table 4.

Table 1 Turbine-generator rotor detailed parameters

\begin{tabular}{llll}
\hline Mass & Shaft & Inertia H (s) & $\begin{array}{c}\text { Spring constant K } \\
\text { (p.u. torque/rad.) }\end{array}$ \\
\hline HP & HP-LP & 0.24894 & 42.702 \\
LP & LP-Gen. & 1.5498 & 83.47 \\
Gen. & 0.8788 & \\
\hline
\end{tabular}

Table 2 Machine electrical parameters

\begin{tabular}{|c|c|c|c|}
\hline \multirow{2}{*}{$\begin{array}{l}\text { Generator } \\
x_{d}\end{array}$} & \multicolumn{3}{|c|}{$600 \mathrm{MVA}, 2$ poles, $60 \mathrm{~Hz}, 20 \mathrm{kV}$} \\
\hline & 1.650 p.u & $x_{q}^{\prime \prime}$ & 0.200 p.u \\
\hline$x_{d}^{\prime}$ & 0.250 p.u & $\mathrm{T}_{\mathrm{do}}{ }^{\prime}$ & $4.50 \mathrm{~s}$ \\
\hline$x_{d}{ }^{\prime}$ & 0.200 p.u & $\mathrm{T}_{\mathrm{do}}^{\prime \prime}$ & $0.04 \mathrm{~s}$ \\
\hline$x_{1}$ & 0.140 p.u & $\mathrm{T}_{\mathrm{qo}}{ }^{\prime}$ & $0.55 \mathrm{~s}$ \\
\hline$x_{q}$ & 1.950 p.u & $\mathrm{T}_{\mathrm{qo}} \prime \prime$ & $0.09 \mathrm{~s}$ \\
\hline$x_{q}^{\prime}$ & 0.460 p.u & $\mathrm{R}$ & 0.0045 p.u \\
\hline
\end{tabular}

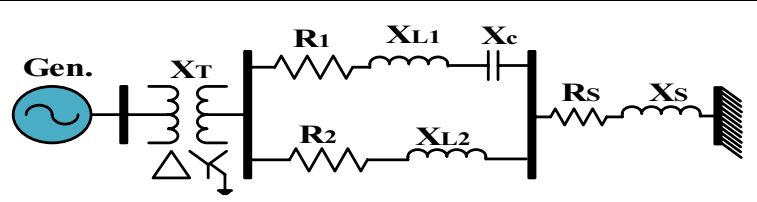

Fig. 11 IEEE second benchmark electrical representation 
Table 3 IEEE second benchmark impedances in p.u

\begin{tabular}{lll}
\hline Parameter & Positive sequence & Zero sequence \\
\hline$R_{T}$ & 0.0002 & 0.0002 \\
$X_{T}$ & 0.0200 & 0.0200 \\
$R_{1}$ & 0.0074 & 0.0220 \\
$X_{L 1}$ & 0.0800 & 0.2400 \\
$R_{2}$ & 0.0067 & 0.0186 \\
$X_{L 2}$ & 0.0739 & 0.2100 \\
$R_{S}$ & 0.0014 & 0.0014 \\
$X_{S}$ & 0.0300 & 0.0300 \\
\hline
\end{tabular}

Table 4 Data of the BES

\begin{tabular}{ll}
\hline BES parameters & \\
\hline Battery bank voltage & $2000 \mathrm{~V}$ \\
Battery inner resistance $\left(R_{\text {int }}\right)$ & $0.004 \Omega$ \\
DC link voltage & $2000 \mathrm{~V}$ \\
Battery bank capacity & $200 \mathrm{MWh}$ \\
Initial SoC & $100 \%$ \\
DC link capacitor & $12,500 \mu \mathrm{F}$ \\
Converter output voltage & $1000 \mathrm{~V}$ \\
Switching frequency & $1.98 \mathrm{kHz}$ \\
IGBT snubber resistance & $10^{6} \mathrm{ohms}$ \\
IGBT snubber capacitance & $\mathrm{InfF}$ \\
IGBT conduction resistance & $10^{-3} \Omega$ \\
IGBT forward voltage & $0 \mathrm{~V}$ \\
Diode forward voltage & $0 \mathrm{~V}$ \\
Inductance filter & $157 \mathrm{mH}$ \\
Proportional gain of voltage PI regulator $\left(\mathrm{K}_{\mathrm{pi}}\right)$ & 2 \\
Integral gain of voltage PI regulator $\left(\mathrm{K}_{\mathrm{ii}}\right)$ & 400 \\
Proportional gain of current PI regulator $\left(\mathrm{K}_{\mathrm{Pu}}\right)$ & 0.3 \\
Integral gain of current PI regulator $\left(\mathrm{K}_{\mathrm{iu}}\right)$ & 20 \\
\hline
\end{tabular}

\section{Abbreviations}

Ah: Ampere hour; BES: Battery-energy-storage; FIS: Fuzzy-inference-system; FLC: Fuzzy-logic-controller; FS: Fuzzyset; Gen.: Generator; GSU: Generator step-up; HP: High-pressure; HP-LP: The shaft section connecting HP turbine to the IP turbine; IGBT: Insulated-gate-bipolar-transistor; LP: Low-pressure; LP-Gen.: The shaft section connecting LP-turbine-to-generator; Max-Min: Maximum-minimum; MF: Membership function; MISO: Multi-input-single-output; MIMO: Multi-input-multi output; MWhr: Megawatt-hour; ND: Negative-deviation; NPC: Neutral-point-clamped; CCP: Common-coupling-point; PD: Positive-deviation; PI: Proportional-integral; PLL: Phase-locked-loop; p.u.: Per-unit; PWM: Pulse-width-modulation; SD: Small-deviation; SIMO: Single-input-multi output; SISO: Single-input-single-output; SoC: State-of-charge; SSR: Sub-synchronous-resonance; TCBR: Thyristor-controlled-brake-resistor; TS: Takagi-Sugeno; VSC: Voltage-source-converter; Xc: Ratio-of-compensation.

\section{Acknowledgements}

Not Applicable.

\section{Authors' contributions}

The authors (MF, FB, ME and MM) presented a Fuzzy logic controller to coordinate the real power injections and the dynamic braking interventions of BESS and TCBR units to help mitigating the unstable subsynchronous resonance oscillations in The IEEE second benchmark test system using MATLAB ${ }^{\mathrm{TM}} /$ Simulink environment. The implemented fuzzy controller utilizes the speed deviation of the synchronous generator as an energization control signal. The individual contribution of each author could be listed as follows. MF did perform the simulation studies and write the manuscript. 
MM did help in designing the simulation environment. ME did help in interpretation of data. FB did help in writing the manuscript. All authors have read and approved the manuscript.

\section{Funding}

The authors are not getting any fund from any organization.

\section{Availability of data and materials}

All the data associated with the considered test system are available in a lot of research papers. The power system simulation is implemented in SimPower ${ }^{\circledR}$ of MATLAB ${ }^{\mathrm{TM}} /$ Simulink which is possible to find the complete system as a demo. R. Champagne and L. Dessaint (Ecole de Technologie Superieure, Montreal), " Sub-synchronous resonance (SSR) in Steam Turbine and Governor on a series-compensated network. ", MATLAB ${ }^{\mathrm{TM}}$ Demo.

\section{Declarations}

Competing interests

The authors declare that they have no competing interests.

\section{Author details}

${ }^{1}$ Cairo Electricity Production Company (CEPC), Cairo, Egypt. ${ }^{2}$ Electrical Engineering Department, Faculty of Engineering Shoubra, Benha University, Cairo, Egypt. ${ }^{3}$ Egyptian Electricity Holding Company (EEHC), Cairo, Egypt.

Received: 3 November 2020 Accepted: 11 March 2021

Published online: 25 March 2021

\section{References}

1. Grigsby LL (2012) Power system stability and control. Taylor \& Francis, Boca Roca

2. Livermore L, Carlos E, Ugalde-Loo MuQ, Liang J, Ekanayake JB, Jenkins N (2014) Damping of subsynchronous resonance using a voltage source converter-based high-voltage directcurrent link in a series-compensated Great Britain transmission network. IET Gener Transm Distrib 8:542-551. https://doi.org/10.1049/iet-gtd.2013.0095

3. Eremia M, Liu CC, Edris AA (2016) Advanced solutions in power systems HVDC, FACTS and artificial intelligence. Wiley, New York

4. Ngamroo I (2018) An integration of optimal superconducting coil into a photovoltaic generator for stabilization of subsynchronous resonance. IEEE Trans Appl Supercond. https://doi.org/10.1109/TASC.2018.2882220

5. Ghorbani A, Pourmohammad S (2010) A novel excitation controller to damp subsynchronous oscillations. Electr Power Energy Syst 33:411-419. https://doi.org/10.1016/j.ijepes.2010.10.002

6. Ghorbani A, Mozaffari B, Ranjbar AM (2012) Application of subsynchronous damping controller (SSDC) to STATCOM. Electr Power Energy Syst 34:418-426. https://doi.org/10.1016/j.ijepes.2012.06.020

7. EPRI Technical Report 107726-R1 (1998) Interconnected power system dynamics tutorial: dynamics of interconnected power systems tutorial, 2nd end. Electric Power Research Institute (EPRI)

8. EPRI Technical Report 1011679 (2005) Steam turbine-generator torsional vibration interaction with the electrical network. Electric Power Research Institute (EPRI)

9. EPRI Technical Report 1013460 (2006) Torsional interaction between electrical network phenomena and turbinegenerator shafts (plant vulnerability). Electric Power Research Institute (EPRI)

10. Xavier LS, Amorim WCS, Cupertino AF, Mendes VF, do Boaventura WC, Pereira HA (2019) Power converters for battery energy storage systems connected to medium voltage systems a comprehensive review. BMC Energy 7:1-15. https://doi.org/10.1186/s42500-019-0006-5

11. Watson D, Rodgers M (2019) Utility-scale storage providing peak power to displace on-island diesel generation. J Energy Storage 22:80-87. https://doi.org/10.1016/j.est.2019.01.028

12. Setiadi $H$, Mithulananthan $N$, Shah $R$, Raghunathan $T$, Jayabarathi T (2019) Enabling resilient wide-area POD at BESS in Java, Indonesia 500 kV power grid. IET Gener Transm Distrib 13:3734-3744. https://doi.org/10.1049/iet-gtd.2018. 6670

13. Zhu Y, Liu C, Sun K, Shi D, Wang Z (2019) Optimization of battery energy storage to improve power system oscillation damping. IEEE Trans Sustain Energy 10:1015-1024. https://doi.org/10.1109/TSTE.2018.2858262

14. Hemmati R, Azizi N (2017) Optimal control strategy on battery storage systems for decoupled active-reactive power control and damping oscillations. J Energy Storage 13:24-34. https://doi.org/10.1016/j.est.2017.06.003

15. Watsona D, Rebelloa E, Kiib N, Finckera T, Rodgersa M (2018) Demand and energy avoidance by a 2 MWh energy storage system in a 10 MW wind farm. J Energy Storage 20:371-379. https://doi.org/10.1016/j.est.2018.10.014

16. Khazaei J, Asrari A, Idowu P, Shushekar S (2019) Sub-Synchronous resonance damping using battery energy storage systems. In: 2018 North American power symposium (NAPS). IEEE. pp 1-6. https://doi.org/10.1109/NAPS.2018.86006 55

17. Ellison JF, Rashkin LJ, Serio J, Byrne RH (2017) The benefits of grid-scale storage on Oahu. J Energy Storage 15:336344. https://doi.org/10.1016/j.est.2017.12.009

18. Menictas C, Skyllas-Kazacos M, Lim TM (2014) Advances in batteries for medium and large-scale energy storage: types and applications. Elsevier, Cambridge

19. Maya GJ, Davidsonb A, Monahovc B (2018) Lead batteries for utility energy storage: a review. J Energy Storage 15:145-157. https://doi.org/10.1016/j.est.2017.11.008

20. Shyam B, Kanakasabapathy P (2018) Large scale electrical energy storage systems in India_current status and future prospects. J Energy Storage 18:112-120. https://doi.org/10.1016/j.est.2018.04.018 
21. Datta U, Kalam A, Shi J (2019) The relevance of large-scale battery energy storage (BES) application in providing primary frequency control with increased wind energy penetration. J Energy Storage 21:489-504. https://doi.org/ 10.1016/j.est.2019.02.013

22. Wong LA, Ramachandaramurthy VK, Taylor P, Ekanayake JB, Walker SL, Padmanaban S (2019) Review on the optimal placement, sizing and control of an energy storage system in the distribution network. J Energy Storage 21:489504. https://doi.org/10.1016/j.est.2018.12.015

23. IEEE Committee Report (1985) Second benchmark model for computer simulation of subsynchronous resonance. IEEE Trans Power Apparat Syst 104(5):1057-1066. https://doi.org/10.1109/MPER.1985.5526570.

24. Ahmed MF, Mandor MA, El-Hadidy M, Bendary FM (2020) Fuzzy based battery energy storage system and braking resistor for mitigation of shaft-torsional oscillations. J King Saud Univ Eng Sci. https://doi.org/10.1016/j.jksues.2020 07.011

25. Rufer A (2017) Energy storage systems and components. Taylor \& Francis Ltd, London

26. Hingorani NG, Gyugyi L (1999) Understanding FACTS: concepts and technology of flexible AC transmission systems. IEEE Press, New York

27. Kundur P (1994) Power system stability and control. McGraw-Hill Inc, New York

28. Rómulo A (2017) Type-2 fuzzy logic uncertain systems' modelling and control. Springer, Singapore

29. Altaş H (2017) Fuzzy logic control in energy systems with design applications. Institution of Engineering \& Technology, Stevenage

30. Castillo O, Melin P (2008) Type-2 fuzzy logic: theory and applications. Springer, Berlin

31. Jantzen J (2013) Foundations of fuzzy control: a practical approach. Wiley, New York

32. Ponce P, Molina A, Cepeda P (2014) Greenhouse design and control. Taylor \& Francis Ltd, London

33. Mendel J, Hagras H, Tan WW, Melek WW, Ying H (2013) Introduction to type-2 fuzzy logic control: theory and applications. Wiley, New York

34. Ali MH, Mikami T, Murata T, Tamura J (2004) A fuzzy logic-controlled braking resistor scheme for damping shaft torsional oscillations. IEEJ Trans Power Energy 124:207-214

\section{Submit your manuscript to a SpringerOpen ${ }^{\circ}$ journal and benefit from:}

- Convenient online submission

- Rigorous peer review

- Open access: articles freely available online

- High visibility within the field

- Retaining the copyright to your article

Submit your next manuscript at $\boldsymbol{\Delta}$ springeropen.com 